\title{
工业涂装行业 VOCs 排放的来源特征及治理技术探讨
}

\author{
装余丹
}

煤科集团杭州环保研究院有限公司

DOI:10.32629/eep.v3i2.674

[摘 要] 工业涂装行业VOCs排放涉及众多行业领域,给大气环境带来了严重危害。本文从工业涂装行业各类涂装工序分析入手,对VOCs排放 的来源特征进行了分析,并对目前工业涂装行业VOCs的治理技术进行了分析比较探讨,并对各废气治理工艺的适用性进行了探讨。

[关键词]工业涂装；VOCs废气；治理技术

\section{引言}

目前我国正处于实施控制VOCs 废气排放的重要阶段, 工业涂装作为 VOCs排放的主要来源。因此, 实现VOCs废气的有效治理是当前工业涂装企 业面临的主要环保责任。

\section{1 工业涂装行业 VOCs 排放的来源特征}

影响工业涂装行业VOCs排放的主要因素有: 涂装工艺、工序; 涂装用 原辅料类型。

1. 1涂装工艺、工序

从涂装工艺来看, 我国涂装行业目前主流的涂装工艺按照原理划分主 要包括:（1)滚刷涂，(2) 空气喷涂，(3) 无空气喷涂，(4) 静电喷涂, (5) 淋 涂, (6) 辊涂, (7) 浸涂, (8) 电泳涂装, (9) 粉末涂装, 其中以喷涂 (空气/无空 气）使用最为广泛。粉末涂装由于不使用有机溶剂, 因而基本不产生VOCs 污染。

\section{2 工业涂装原辅料类型}

工业涂装行业VOCs 主要来源于涂料/油漆, 稀释剂 (溶剂), 固化剂, 胶 黏剂和清洗剂等有机溶剂的使用。涂料根据溶剂的不同可划分为溶剂型涂 料、水性涂料和UV涂料。溶剂型涂料是指完全以有机物为溶剂的涂料, 涂 料中VOCs 含量高, 使用过程中必须加入有机溶剂作为稀释, 因此溶剂型涂 料是涂装行业VOCs主要来源。

根据调查, 涂装工艺中物料中VOCs 含量, 粉末涂料VOCs 含量 $2 \%$, 水性涂 料VOCs 含量 $15 \%$, 稀释剂VOCs 含量 $100 \%$, 固化剂VOCs 含量 $40-45 \%$, 清洗剂 VOCs 含量 $100 \%$, 废气中具体VOCs组分一般包括二甲苯、甲苯、乙苯、三甲 苯、乙酸乙酯、乙酸丁酯等。

\section{2 工业涂装 VOCs 控制技术现状}

工业VOCs控制分为源头控制和末端治理两部分。

从源头控制上来看, 就工业涂装行业而言, 使用符合环境标志产品技 术要求的水性涂料, 是涂装行业降低VOCs排放的根本性方向。此外, 涂装工 艺的改进也可以减少VOCs的排放, 使用涂装效率较高的静电喷涂、淋涂、辊 涂、浸涂等代替涂装效率较低的空气喷涂、滚刷涂和手工涂装等, 采用涂 装效率高的涂装工艺进行密闭涂装可以大幅减少VOCs排放。

从未端治理来看, 目前国内外涂装行业常用的VOCs治理技术包括有焚 烧技术 (包括直燃炉、R T0、工艺炉焚烧等) 、直接催化燃烧技术、活性炭 吸附-脱附一催化燃烧技术、低温等离子技术、光催化技术、水/酸/碱吸收 技术、一次性活性炭技术等。
虽然目前工业涂装VOCs 治理已经得到了地方各级政府和环境管理部 门的高度重视, 在VOCs 治理方面也取得了一定的进展, 但总体的治理效果 却并不理想。工业涂装VOCs 治理尚处于起步阶段。存在废气收集效率低, 治理措施覆盖率低, 废气治理不全, 去除效率低, 设施疏于管理等问题。在 一些地区, 还在大面积使用低温等离子、光催化、光氧化等低效技术。

\section{3 各废气治理工艺的适用性探讨}

VOCs 废气组分复杂, 治理技术多样, 适用性差异大, 在实际的工程应用 中, 如何经济合理地选取实用的处理技术是治理的关键。很有必要根据废 气治理的实践总结推进建设适宜高效的治理工艺方案, 这也是VOCs 治理工 作从发展阶段过渡到成熟阶段的必然进程。

目前大部分工业涂装企业VOCs 治理效率低下, 不能合理选择适用的治理 技术也是一个重要的原因。根据我们对企业VOCs治理的实践经验总结如下:

(1) 高浓度废气, 优先进行溶剂回收, 难以回收的, 宜采用高温焚烧、催 化燃烧等技术进行净化处理。(2) 对于低浓度、大风量的VOCs 废气, 宜采用 沸石转轮吸附、活性炭吸附、减风增浓等浓缩技术, 提高VOCs 浓度后再净 化处理。(3) 生物法主要适用于低浓度VOCs废气治理。(4) 针对小型污染源, 活性炭吸附是一种有效的低成本的净化方式, 采用一次性活性炭吸附技术 的, 应定期更换活性炭, 提高VOCs 治理效率。(5) 低温等离子、光催化、光 氧化技术由于实际处理效率较低. 一般不适合作为工业涂装企业VOCs 治理 方案。

\section{4 结论与建议}

(1) 建议工业涂装VOCs 废气治理从环境友好型原辅料入手, 从源头上 控制VOCs 产生。(2) 通过提高工业涂装先进技术装备, 削减废气量, 完善废 气收集能力, 并大力推广焚烧、吸附浓缩催化燃烧等先进治理技术, 提高 VOCs 废气治理效率, 有效减少工业涂装 VOCs排放。

[参考文献]

[1]陆建海,董事壁,李文娟,等.浙江省工业涂装VOCs治理现状[J].环境 保护科学,2018,(1):113-117.

[2] 叶红.VOC 废气治理工程技术方案探究 [J]. 资源节约与环 保,2017,(12):45-47.

[3]陈子林.VOC废气治理工程技术方案探究[J].科技视界,2019,(18):84-85. 作者简介：

装余丹(1965--), 男, 浙江省杭州市人, 汉族, 大学本科, 高级工程师, 煤科集团杭州环保研究院有限公司, 研究方向: 环保及科技管理。 